\title{
Study of Nutritional Status and Gastrointestinal Health in Patients Undergoing Hemodialysis and their Association with Laboratory Parameters and Dialysis Adequacy in Semnan, Iran
}

\author{
Zaynab Hydarinia-Naieni, ${ }^{1}$ Monir Nobahar, ${ }^{2,3,}{ }^{*}$ and Raheb Ghorbani ${ }^{4}$ \\ ${ }^{1}$ Nursing Care Research Center, Faculty of Nursing and Midwifery, Semnan University of Medical Sciences, Semnan, IR Iran \\ ${ }^{2}$ Nursing Care Research Center, Semnan University of Medical Sciences, Semnan, IR Iran \\ ${ }^{3}$ Department of Nursing, Faculty of Nursing and Midwifery, Semnan University of Medical Sciences, Semnan, IR Iran \\ ${ }^{4}$ Social Determinants of Health Research Center, Department of Epidemiology and Biostatistics, Faculty of Medicine, Semnan University of Medical Sciences, Semnan, IR Iran \\ "Corresponding author: Monir Nobahar, (BScN, MSc, PhD), Associate Professor, Nursing Care Research Center, Faculty of Nursing and Midwifery, Semnan University of Medical \\ Sciences, Semnan, IR Iran. Tel: +98-23133654190, Fax: +98-23133654209, E-mail: nobahar43@semums.ac.ir
}

Received 2017 May 06; Accepted 2017 May 20.

\begin{abstract}
Background: Malnutrition is a common problem, which may exacerbate gastrointestinal symptoms, reduce treatment efficiency, and deteriorate hemodynamic stability in hemodialysis (HD) patients.

Objectives: This study aimed to investigate nutritional status and gastrointestinal health in HD patients and to determine the association of these variables with laboratory parameters and dialysis adequacy in Semnan, Iran in 2016.

Methods: This cross sectional study was conducted on 80 patients with a minimum 6-month history of HD. Gastrointestinal health and nutritional status were assessed using gastrointestinal symptom rating scale and subjective global assessment, respectively. The laboratory parameters included alkaline phosphatase, urea, creatinine, albumin, iron, hemoglobin, hematocrit, and blood sugar. Results: Overall, $27.5 \%$ of the patients had mild to moderate malnutrition, while $72.5 \%$ had a good nutritional status. The most common digestive problem was constipation (83.7\%). Calcium intake $(r=0.2313 ; \mathrm{P}=0.046)$, creatinine $(\mathrm{r}=0.234 ; \mathrm{P}=0.041)$, and alkaline phosphatase $(\mathrm{r}=0.414 ; \mathrm{P}<0.001)$ showed a positive correlation with gastrointestinal health. In addition, alkaline phosphatase $(\mathrm{r}=$ $0.419 ; \mathrm{P}<0.001)$ had a positive relationship with nutrition. HD adequacy was $>0.8$ in $15 \%$ and $\geq 1.20$ in $11.3 \%$ of the patients. HD adequacy $(r=0.260 ; P=0.023)$, urea nitrogen $(r=0.228, P=0.046)$, and creatinine $(r=0.330 ; P=0.003)$ had a positive correlation with gastrointestinal health. Overall, there was a significant positive correlation between nutrition and gastrointestinal health $(\mathrm{r}=$ 0.799; $\mathrm{P}<0.001)$.

Conclusions: The present findings can facilitate better planning to improve nutritional status, gastrointestinal health, laboratory parameters, and dialysis adequacy in the management of HD patients, particularly those with malnutrition.
\end{abstract}

Keywords: Hemodialysis, Nutritional Status, Gastrointestinal Symptom, Laboratory Parameters, Dialysis Adequacy

\section{Background}

Chronic renal failure (CRF) refers to the irreversible loss of kidney function over a period of more than 3 months. End-stage renal disease (ESRD) is the final stage of CRF, which occurs when the kidneys stop functioning adequately to keep a person alive. In ESRD patients, dialysis or kidney transplant is integral to survival (1). Moreover, uremic toxins, metabolic acidosis, HD incompetence, poor gastric emptying, side effects of medications, psychosocial factors, and history of gastrointestinal diseases in ESRD are associated with digestive disorders (2).

Overall, gastrointestinal disorders are common in HD patients. According to statistics, 51\% of these patients have at least 1 digestive problem and $14 \%$ have reduced food intake (3). Some sources have reported that the prevalence of such disorders in HD patients varies from 32\% to $79 \%$ (4, 5). In this regard, Dong et al. (2014) reported a prevalence of 76.4\% for gastrointestinal symptoms in HD patients (6). In addition, Bossola et al. (2011) showed that $23.6 \%$ of HD patients had aversion to frequent meals, $18.2 \%$ had early satiety, 3.6\% experienced changes in the sense of smell, and $7.2 \%$ had changes in the sense of taste (7).

Multiple gastrointestinal symptoms are among the underlying causes of malnutrition in HD patients (8). Malnutrition in these patients results from reduced nutrient intake, psychological, hormonal, and metabolic factors (such as acidosis, inflammation, resistance to anabolic agents, insulin resistance, and disorders associated with advanced kidney disease), side effects of renal replacement therapy, advancing age, and other diseases (9). Moreover, chronic systemic inflammation associated with HD (3), anorexia, depression, difficulties in chewing, and socioeconomic barriers can lead to malnutrition (10). Meanwhile, malnutrition, weight loss, slimming, and complex 
conditions are usually undiagnosed and remain untreated in more than $70 \%$ of patients (8).

According to previous reports, the prevalence of malnutrition was significantly lower in 2014 (18\%), compared to 1986 (52\%) (11). In this regard, another study examined the nutritional status of $105 \mathrm{HD}$ patients using the Subjective Global Assessment (SGA) questionnaire. As the findings revealed, $93.3 \%$ of the patients had mild and moderate malnutrition, while $2.86 \%$ had severe malnutrition; overall, $96.19 \%$ of the patients suffered from malnutrition (12). Additionally, malnutrition is associated with low quality of life (physical and mental components) (13). Considering its influence on the immune system, infection control is considered as an important risk factor for prolonged side effects (14), clinical complications (11), and increased mortality in HD patients $(15,16)$.

Nutritional health is of grave significance in HD patients (9). Evidence indicates that restricted eating in HD patients may deteriorate their nutritional status (17). Therefore, nutritional status monitoring should include a monthly assessment of serum albumin and dry weight, as well as SGA administration once every 3 - 6 months (9). Overall, the goal of treatment includes optimization of nutritional status (18). However, there is inadequate information about the nutritional status of HD patients in Semnan, Iran. Therefore, considering the high prevalence of malnutrition and variety of gastrointestinal symptoms, periodic evaluation is necessary for HD patients (12).

In a previous study, laboratory parameters were related to poor physical conditions of HD patients and were significantly associated with all-cause mortality (19). These parameters were used to predict the outcomes of HD patients (20). In clinical practice, physicians attempt to maintain the level of these parameters within the normal range (19). It seems that these parameters might influence nutritional status and gastrointestinal health in HD patients.

Furthermore, HD adequacy is an important factor in reducing the risk of various complications (21). Urea removal has become a key indicator of dialysis intensity and comprehensive clinical and dialysis-related measures (22). Half of HD patients do not experience optimal HD adequacy, and multiple demographic and personal factors seem to affect HD adequacy either directly or conversely (21). The authors believe that urea clearance or Kt/V ratio, as a marker of dialysis adequacy, may be associated with nutritional status and gastrointestinal symptoms, which can be assessed for treatment planning and early treatment of disorders.

\section{Objectives}

The objective of the present study was to assess nutritional status and gastrointestinal health in HD patients and to determine the association of these variables with laboratory parameters and HD adequacy in Semnan, Iran.

\section{Methods}

\subsection{Sampling and Data Collection}

This descriptive cross sectional study was conducted in 2016. The samples were selected using convenience and census sampling among all HD patients. Among $90 \mathrm{HD}$ patients, 80 met the inclusion criteria and were selected for the study. Patients in the HD ward of Kowsar Hospital of Semnan with at least a 6-month history of HD (2 to 3 sessions per week, 4 hours each session) and full consciousness were selected.

On the other hand, the exclusion criteria were as follows: 1) history of gastrointestinal diseases before HD according to the patient's self-report;2) unwillingness to participate in the study; and 3) transfer or death of the patient. Data were collected using the demographic questionnaire, Gastrointestinal Symptom Rating Scale(GSRS) for gastrointestinal health, and SGA for nutritional status.

GSRS contains 15 questions on a 7-point Likert scale, scored from 0 (no discomfort) to 7 (severe discomfort), with higher scores indicating severe symptoms (5). The total score is measured by summing the mean scores of each subscale. Overall, increased score on this scale indicates the severity of symptoms. The questionnaire is completed by interview or self-report. The validity and reliability of GSRS has been reported to be "good to satisfactory" in some international studies; also, its internal consistency has been reported to be 0.61 - 0.91 (23).

Initially, the tool was translated and then evaluated in terms of psychiatric features. Its validity was determined using qualitative and quantitative methods of content and face validity, respectively. The translated tool was presented to 7 professors in order to determine its face and content validity; the experts' comments were applied to improve the items of the questionnaire. The tool was presented to 10 professors in order to determine its content validity index, using Waltz and Bausell methods (0.85). In terms of reliability, Cronbach's alpha was used to assess the internal consistency of the tool (0.88) (24).

On the other hand, SGA is a tool used by healthcare providers to assess nutritional status in HD patients (12). The scores are calculated based on 7 variables, including weight variations over the past 2 weeks to 6 months, 
changes in food consumption, presence of gastrointestinal symptoms, changes in the functional status, alterations in the loss of subcutaneous fat, loss of muscle, and inflation. Based on this system, the patients were divided into 3 groups of good nutrition or healthy, mild or moderate malnutrition, and severe malnutrition.

According to the self-reports and Likert scores, each variable is rated from 1 to 7 ; the minimum and maximum total scores are 7 and 49 , respectively. Scores 1 - 14 indicate good nutrition, scores 15 - 35 represent mild to moderate malnutrition, and scores 36 - 49 show severe malnutrition. This questionnaire is the best tool to measure nutritional status in HD patients (12).

SGA is a validated tool, which determines the current nutritional status of an individual (18). In the present study, if the patient had sufficient literacy, he/she would individually answer the questionnaire. In case of any ambiguity while completing the questionnaire, the subject received adequate explanations. If the patient did not have sufficient literacy, the questions and options would be read to the patients and their answers would be recorded in the questionnaire.

The laboratory parameters included alkaline phosphatase, urea, creatinine, albumin, iron, hemoglobin, hematocrit and blood sugar. In addition, HD adequacy was calculated with urea clearance using Kt/V ratio (K, dialyzer urea clearance; $t$, dialysis time; $v$, urea distribution volume). National standards and guidelines of the Ministry of Health for specific diseases have introduced an acceptable level of 1.2 for Kt/V ratio as the minimum HD adequacy. Suitable HD adequacy in this study was Kt/V ratio of at least 1.2. In Iran, $\mathrm{HD}$ adequacy (KT/V) has been reported to be more than 1.2 with a confidence interval of 26.4 - 46.2 (36.3\%) (25). Overall, $\mathrm{Kt} / \mathrm{V}$ is the most tested measure of dialyzer effect on HD patient survival and is the most frequently applied measure of delivered dialysis dose (26).

\subsection{Ethical Considerations}

This study was approved by the ethics committee of Semnan University of Medical Sciences. Initially, general explanations on the research design and procedures were presented to the HD patients. If the patient was willing to cooperate, he/she would sign a consent form and the questionnaire would be completed.

\subsection{Data Analysis}

For data analysis, Chi square, Fisher's exact test, MannWhitney test, Kruskal-Wallis test, partial correlation coefficient, and logistic regression analysis were performed, using SPSS version 18 at a significance level of 0.05 .

\section{Results}

Distribution of the demographic characteristics of HD patients is presented in Table 1. Among 80 HD patients, $27.5 \%$ had mild to moderate malnutrition, while the rest (72.5\%) had a good nutritional status. In the univariate and multiple analyses, none of the studied variables had a significant relationship with nutritional status (Table 1 ).

With regard to gastrointestinal health, the mean severity of gastrointestinal symptoms in HD patients was $8.56 \pm$ 6.97. The most common gastrointestinal symptoms were constipation (83.8\%) and abdominal distention (71.3\%). Less common symptoms included diarrhea (2.5\%) and loose stool (3.8\%). All these symptoms (except for abdominal distention and loose stool) were significantly associated with the prevalence of malnutrition $(\mathrm{P}<0.05)$ (Table 2$)$.

Among the studied variables, calcium $(\mathrm{r}=0.2313$; $\mathrm{P}=$ 0.046), marital status $(\mathrm{P}=0.004)$, and smoking $(\mathrm{P}=0.014)$ had a positive correlation with gastrointestinal health. More symptoms appeared by increasing daily calcium intake. In addition, widowed patients and smokers had more gastrointestinal symptoms (Table 3).

Suitable HD adequacy ( $\geq 1.20$ ) was reported in $11.3 \%$ of the subjects. Additionally, HD adequacy was $<0.8$ in $15 \%$ of the subjects, while the rest of the patients were in the range of $0.8-1.19$. Based on the findings, HD adequacy was associated with income $(\mathrm{P}=0.022)$. In fact, HD adequacy was better in subjects with lower income. On the other hand, HD adequacy had no significant relationship with other characteristics of the patients (Table 4).

Among the laboratory parameters, only alkaline phosphatase had a positive relationship with nutritional status $(\mathrm{r}=0.419 ; \mathrm{P}<0.001)$. Indices of creatinine $(\mathrm{r}=0.234 ; \mathrm{P}=$ $0.041)$ and alkaline phosphatase $(\mathrm{r}=0.414 ; \mathrm{P}<0.001)$ had a positive correlation with gastrointestinal health. In addition, HD adequacy had a positive correlation with urea nitrogen $(\mathrm{r}=0.228 ; \mathrm{P}=0.046)$ and creatinine $(\mathrm{r}=0.330 ; \mathrm{P}=$ 0.003 ) (Table 5).

There was no significant relationship between HD adequacy and nutritional status $(\mathrm{r}=0.109 ; \mathrm{P}=0.344)$. A positive correlation was observed between HD adequacy and gastrointestinal health $(\mathrm{r}=0.260 ; \mathrm{P}=0.023)$. The mean \pm SD severity of gastrointestinal symptoms was $4.4 \pm 6.1$ in patients with a normal nutritional status and $8.4 \pm 0.15$ in patients with mild to moderate malnutrition. There was a positive correlation between nutrition and gastrointestinal health in HD patients $(\mathrm{r}=0.799 ; \mathrm{P}<0.001)$.

\section{Discussion}

The results of the present study indicated that $92.5 \%$ of HD patients had at least 1 gastrointestinal symptom, and 
Table 1. Nutritional Status Based on the Demographic Characteristics of Patients Undergoing Hemodialysis (HD) in Semnan, Iran, $2016^{\text {a }}$

\begin{tabular}{|c|c|c|c|c|c|c|}
\hline \multirow{2}{*}{$\begin{array}{l}\text { Demographic } \\
\text { Characteristics }\end{array}$} & & \multicolumn{3}{|c|}{ Nutritional Status } & \multirow[t]{2}{*}{ Partial Correlation } & \multirow[t]{2}{*}{ P Value } \\
\hline & & Normal & Mild to Moderate & Malnutrition & & \\
\hline \multirow{2}{*}{ Gender } & Female & $33(41.2)$ & $26(78.8)$ & $7(21.2)$ & \multirow{2}{*}{-} & \multirow{2}{*}{0.291} \\
\hline & Male & $47(58.8)$ & $32(68.1)$ & $15(31.9)$ & & \\
\hline \multirow{3}{*}{ Marital status } & Single & $8(10)$ & $8(100)$ & - & \multirow{3}{*}{-} & \multirow{3}{*}{0.575} \\
\hline & Married & $66(82.5)$ & $47(71.2)$ & $19(28.8)$ & & \\
\hline & Widow & $6(7.5)$ & $3(50)$ & $3(50)$ & & \\
\hline \multirow{3}{*}{ Educational level } & Illiterate & $26(32.5)$ & $16(61.5)$ & $10(38.5)$ & \multirow{3}{*}{-0.1707} & \multirow{3}{*}{0.143} \\
\hline & Primary & $34(42.5)$ & $26(76.5)$ & $8(23.5)$ & & \\
\hline & Diploma or higher & $20(25)$ & $16(80)$ & $4(20)$ & & \\
\hline \multirow[t]{2}{*}{ Occupational status } & Housewife & $33(41.3)$ & $26(78.8)$ & $7(21.2)$ & \multirow[t]{2}{*}{ - } & \multirow[t]{2}{*}{0.296} \\
\hline & Unemployed & $36(45)$ & $26(72.2)$ & $10(27.8)$ & & \\
\hline \multirow{2}{*}{ Age, $y$} & $<50$ & $18(22.5)$ & $14(77.8)$ & $4(22.2)$ & \multirow{2}{*}{0.1671} & \multirow{2}{*}{0.152} \\
\hline & $\geq 50$ & $62(77.5)$ & $44(71)$ & $18(29)$ & & \\
\hline \multirow{2}{*}{ Aspirin use } & + & $32(40)$ & $25(78.1)$ & $7(21.9)$ & \multirow{2}{*}{-} & \multirow{2}{*}{0.358} \\
\hline & - & $48(60)$ & $33(68.8)$ & $15(31.3)$ & & \\
\hline \multirow{2}{*}{ Smoking } & + & $7(8.7)$ & $4(57.1)$ & $3(42.9)$ & \multirow{2}{*}{-} & \multirow{2}{*}{0.341} \\
\hline & - & $73(91.3)$ & $54(74)$ & $19(26)$ & & \\
\hline \multirow{2}{*}{ Alcohol use } & + & $1(1.2)$ & $1(100)$ & - & \multirow{2}{*}{ - } & \multirow{2}{*}{1} \\
\hline & - & $79(98.8)$ & $57(72.2)$ & $22(27.8)$ & & \\
\hline
\end{tabular}

${ }^{\mathrm{a}}$ Values are expressed as No. (\%).

only 7.5\% had no gastrointestinal symptoms. A study by Daniels et al. (2015) in the USA demonstrated that at least 90\% of HD patients had a gastrointestinal symptom; the most common gastrointestinal symptoms included dyspepsia, abdominal pain, and constipation (27). In addition, our findings indicated that $17.5 \%$ of the patients had 1 to 3 symptoms, and $75 \%$ had more than 3 gastrointestinal symptoms.

Furthermore, the findings of a study in China demonstrated that $14.8 \%$ of HD patients had more than one gastrointestinal symptom (6). In addition, Salamon et al. (2013) stated that 51\% of HD patients in Australia complained of at least 1 gastrointestinal symptom (3). The most common symptoms were constipation (83.8\%) and abdominal distention (71.3\%). Bossola et al. (2011) indicated that the most common gastrointestinal symptoms in HD patients were abdominal distention and constipation (7). Additionally, Dong et al. (2014) showed that constipation was the most common symptom in HD patients (6).

Among the laboratory parameters, creatinine and alka- line phosphatase had a positive correlation with gastrointestinal health. It was shown that patients with CRF and higher levels of urea were at a higher risk of gastrointestinal symptoms (28). Moreover, Tomizawa et al. demonstrated that patients with a urea level above 21 might experience more severe gastrointestinal problems (29). In fact, high levels of urea were associated with gastrointestinal conditions. However, patients in this study were undergoing HD, and urea level was not significantly associated with gastrointestinal health. Considering the relationship of gastrointestinal health with alkaline phosphatase and creatinine, we suggest further research in this field in the future.

The level of calcium intake had a significant positive relationship with gastrointestinal health; more severe gastrointestinal symptoms emerged by increasing daily calcium intake. Moreover, Wang et al. stated that the main side effects of treatment with calcium supplements are gastrointestinal symptoms, including stomachache, abdominal distension, nausea, and anorexia (30). 
Table 2. Severity of Gastrointestinal Symptoms in Patients Undergoing Hemodialysis (HD) in Semnan, Iran, 2016 ${ }^{\mathrm{a}}$

\begin{tabular}{|c|c|c|c|c|c|c|}
\hline \multirow[t]{2}{*}{ Gastrointestinal Symptoms } & \multicolumn{5}{|c|}{ Severity of Gastrointestinal Symptoms } & \multirow[t]{2}{*}{ Mean (SD) } \\
\hline & $\mathbf{0}$ & $\mathbf{1}$ & 2 & 3 & 4 & \\
\hline Stomachache & $30(37.5)$ & $43(53.8)$ & $7(8.8)$ & - & - & $0.71(0.62)$ \\
\hline Heartburn & $25(31.3)$ & $44(55)$ & $10(12.5)$ & $1(1.3)$ & - & $0.84(0.68)$ \\
\hline Reflux & $64(80)$ & $10(12.5)$ & $5(6.3)$ & $1(1.3)$ & - & $0.29(0.64)$ \\
\hline Abdominal pain & $53(66.3)$ & $23(28.8)$ & $4(5)$ & - & - & $0.39(0.58)$ \\
\hline Nausea & $56(70)$ & $19(23.8)$ & $5(6.3)$ & - & - & $0.36(0.60)$ \\
\hline Abdominal sounds & $59(73.8)$ & $18(22.5)$ & $2(2.5)$ & $1(1.3)$ & - & $0.31(0.59)$ \\
\hline Bloating & $23(28.8)$ & $39(48.8)$ & $16(20)$ & $2(2.5)$ & - & $0.96(0.77)$ \\
\hline Belching & $46(57.5)$ & $24(30)$ & $9(11.3)$ & $1(1.3)$ & - & $0.56(0.74)$ \\
\hline Gas disposal & $38(47.5)$ & $30(37.5)$ & $10(12.5)$ & $2(2.5)$ & - & $0.70(0.77)$ \\
\hline Constipation & $13(16.3)$ & $18(22.5)$ & $30(37.5)$ & $17(21.3)$ & 2.5 & $1.71(1.06)$ \\
\hline Diarrhea & $78(97.5)$ & - & $1(1.3)$ & $1(1.3)$ & - & $0.06(0.4)$ \\
\hline Loose stool & $77(96.3)$ & $1(1.3)$ & $2(2.5)$ & - & - & $0.06(0.33)$ \\
\hline Hard stool & $30(37.5)$ & $25(31.3)$ & $20(25)$ & $3(3.28)$ & 2.5 & $1.02(1.01)$ \\
\hline Need for immediate disposal & $74(92.5)$ & $2(2.5)$ & $3(3.8)$ & $1(1.3)$ & - & $0.14(0.52)$ \\
\hline Incomplete bowel evacuation & $60(75)$ & $9(11.3)$ & $8(10)$ & $2(2.15)$ & 1.3 & $0.44(0.87)$ \\
\hline
\end{tabular}

${ }^{\mathrm{a}}$ Values are expressed as No. (\%).

In a study on the effects of calcium supplements on the incidence of constipation in healthy women, the results demonstrated that daily intake of $500 \mathrm{mg}$ of calcium phosphate and calcium carbonate does not affect the frequency of defecation (31). However, HD patients continuously used larger amounts of calcium supplements. Based on the findings, marital status and smoking had a significant positive correlation with gastrointestinal health. In addition, widowed patients and smokers had increased gastrointestinal symptoms. We believe that the stress caused by the partner's death could lead to an increase in digestive disorders. Smoking is also a major risk factor for gastrointestinal disorders.

The findings of the present study indicated that HD adequacy, urea nitrogen, and creatinine level had a significant and positive relationship with gastrointestinal health. There are some controversial reports on HD adequacy and biochemical parameters (25). In a previous study, a significant positive correlation was found between albumin and Kt/V ratio. However, other laboratory variables, including hemoglobin, calcium, phosphorus, and alkaline phosphatase, had no significant correlation with $\mathrm{Kt} / \mathrm{V}$ ratio (32). HD adequacy and gastrointestinal health may be improved in patients by using measures such as larger dialysis filters, longer duration of HD, and increasing the HD machine rate to the allowable level with respect to the patient's tolerability.

The present findings indicated that $27.5 \%$ of patients had mild to moderate malnutrition, while the rest $(72.5 \%)$ had a good nutritional status. In the univariate and multiple logistic regression analyses, none of the variables were significantly associated with nutritional status. These results are consistent with a study by Todd et al. in terms of the prevalence of malnutrition. In their study, mild to moderate malnutrition was observed in $35 \%$ of native patients and $25 \%$ of non-indigenous Australian patients (18). In this study, no severe malnutrition was observed in any of the patients. In addition, in a previous study, 8.4\% of patients had a good nutritional status, $47.4 \%$ showed mild malnutrition, and $44.2 \%$ had moderate malnutrition. However, no cases of severe malnutrition were reported (33).

The present data showed that only alkaline phosphatase among the laboratory parameters had a significant positive correlation with nutritional status. Biochemical parameters such as hemoglobin, albumin, cholesterol, urea nitrogen, and creatinine had no significant correlation with malnutrition. However, in another study, no significant relationship was observed between malnutrition and biochemical parameters such as hemoglobin, albumin, cholesterol, urea nitrogen, and creatinine (12).

Lack of a significant correlation between biochemical 
Table 3. Mean, Standard Deviation (SD), Median, and Interquartile Range of Gastrointestinal Symptoms Based on the Demographic Characteristics of Patients Undergoing Hemodialysis (HD) in Semnan, Iran, 2016

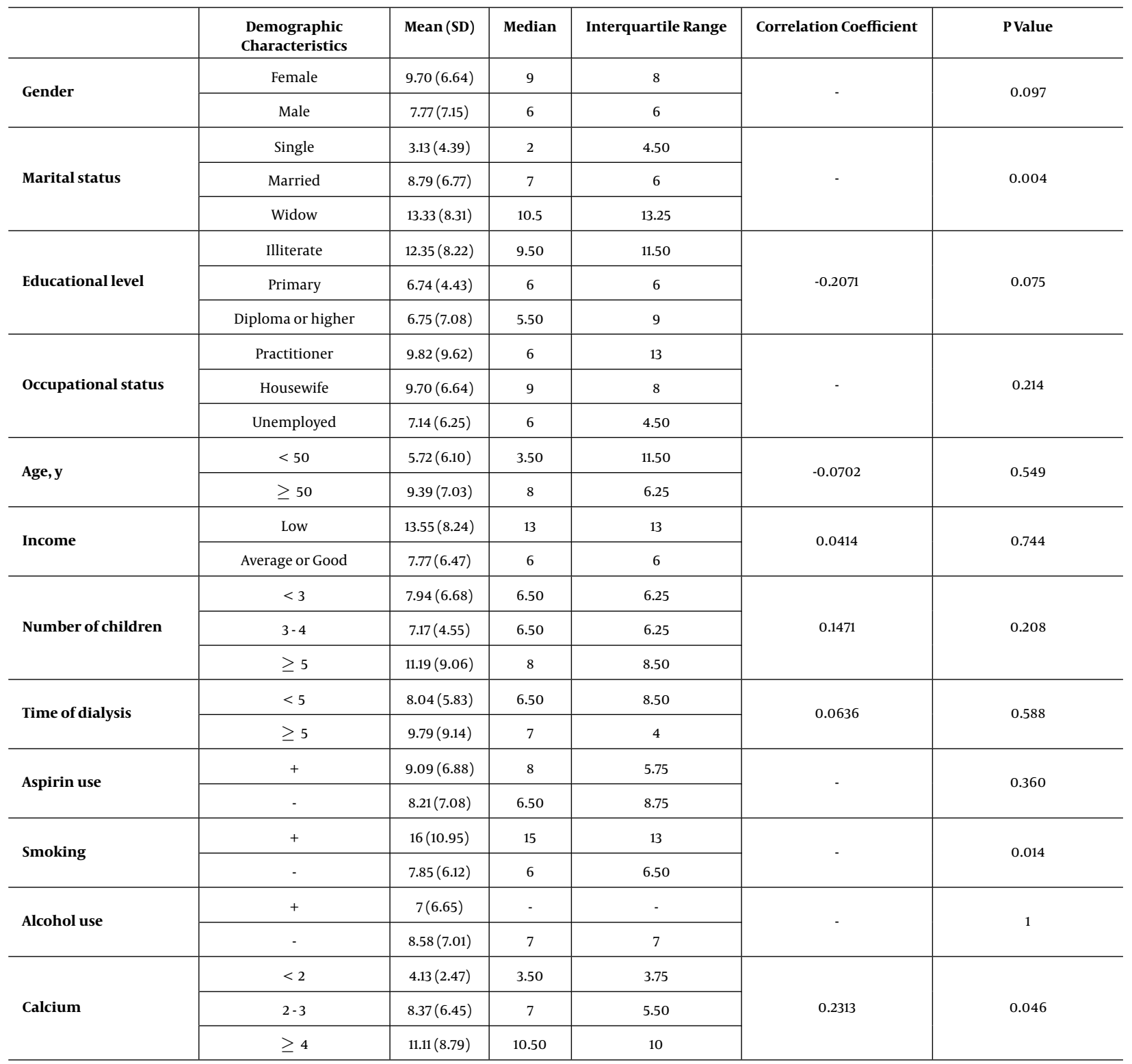

indices and malnutrition indicates that these indices cannot provide accurate information about the nutritional status of HD patients (12). In this study, there was no significant relationship between nutritional status and albumin level. In addition, Chen et al. reported no significant variation in the severity of malnutrition and serum albumin (34).

The present results indicated a significant positive correlation between HD adequacy and gastrointestinal health. However, there was no significant positive correla- tion between nutritional status and HD adequacy, whereas gastrointestinal health and nutritional status showed a significant and positive relationship. In this regard, Chumlea et al. showed that promotion of dialysis adequacy could improve the nutritional status of HD patients (35). Therefore, HD patients should be assessed in terms of management of gastrointestinal symptoms. Moreover, use of drugs likely to cause or aggravate gastrointestinal symptoms should be reported (3).

One of the limitations of this study was the small num- 
Table 4. Distribution of Mean and Standard Deviation (SD) of Hemodialysis (HD) Adequacy Based on the Demographic Characteristics of Patients in Semnan, Iran, 2016 ${ }^{\text {a }}$

\begin{tabular}{|c|c|c|c|c|c|c|}
\hline \multirow[t]{2}{*}{ Demographic Characteristics } & & \multicolumn{3}{|c|}{ Dialysis Adequacy } & \multirow[t]{2}{*}{ Mean (SD) } & \multirow[t]{2}{*}{ P Value } \\
\hline & & $<0.8$ & $0.8-1.19$ & $\geq 1.20$ & & \\
\hline \multirow{2}{*}{ Gender } & Female & $2(6.1)$ & $27(81.8)$ & $4(12.1)$ & $0.99(0.16)$ & \multirow{2}{*}{0.506} \\
\hline & Male & $10(21.3)$ & $32(68.1)$ & $5(10.6)$ & $0.96(0.21)$ & \\
\hline \multirow{3}{*}{ Marital status } & Single & - & $6(75)$ & $2(25)$ & $1.09(0.14)$ & \multirow{2}{*}{0.109} \\
\hline & Widow & - & $4(66.7)$ & $2(33.3)$ & $1.01(0.20)$ & \\
\hline & Illiterate & $3(11.5)$ & $20(76.9)$ & $3(11.5)$ & $0.96(0.17)$ & \\
\hline \multirow[t]{2}{*}{ Educational level } & Primary & $6(17.6)$ & $24(70.6)$ & $4(11.8)$ & $0.98(0.22)$ & \multirow{2}{*}{0.883} \\
\hline & Diploma or higher & $3(15)$ & $15(75)$ & $2(10)$ & $0.97(0.16)$ & \\
\hline \multirow{3}{*}{ Occupational status } & Practitioner & $2(18.2)$ & $7(63.6)$ & $2(18.2)$ & $1.01(0.20)$ & \multirow{3}{*}{0.443} \\
\hline & Housewife & $2(6.1)$ & $27(81.8)$ & $4(12.1)$ & $0.99(0.16)$ & \\
\hline & Unemployed & $8(22.2)$ & $25(69.4)$ & $3(8.3)$ & $0.94(0.21)$ & \\
\hline \multirow{2}{*}{ Age, y } & $<50$ & $2(11.1)$ & $13(72.2)$ & $3(16.7)$ & $1.01(0.18)$ & \multirow{2}{*}{0.330} \\
\hline & $\geq 50$ & $10(16.1)$ & $46(74.2)$ & $6(9.7)$ & $0.96(0.19)$ & \\
\hline \multirow{2}{*}{ Income } & Low & - & $7(63.6)$ & $4(36.4)$ & $1.09(0.17)$ & \multirow{2}{*}{0.022} \\
\hline & Average or good & $12(17.4)$ & $52(75.4)$ & $5(7.2)$ & $0.95(0.19)$ & \\
\hline \multirow{3}{*}{ Number of children } & $<3$ & $5(14.3)$ & $27(77.1)$ & $3(8.6)$ & $0.96(0.16)$ & \multirow{3}{*}{0.887} \\
\hline & $3-4$ & $4(16.7)$ & $16(66.7)$ & $4(16.7)$ & $0.99(0.23)$ & \\
\hline & $\geq 5$ & $3(14.3)$ & $16(76.2)$ & $2(9.5)$ & $0.97(0.20)$ & \\
\hline Time of dialysis & $\geq 5$ & $9(16.1)$ & $42(75)$ & $5(8.9)$ & $1.01(0.19)$ & 0.184 \\
\hline Aspirin use & - & $7(14.6)$ & $35(72.9)$ & $6(12.5)$ & $0.98(0.18)$ & 0.443 \\
\hline \multirow{2}{*}{ Smoking } & + & $1(14.3)$ & $6(85.7)$ & - & $1.02(0.17)$ & \multirow{2}{*}{0.466} \\
\hline & - & $11(15.1)$ & $53(72.6)$ & $9(12.3)$ & $0.96(0.19)$ & \\
\hline \multirow{2}{*}{ Alcohol use } & + & - & $1(100)$ & - & 1.18 & \multirow{2}{*}{ - } \\
\hline & - & $12(15.2)$ & $58(73.4)$ & $9(11.4)$ & $0.97(0.19)$ & \\
\hline \multirow{3}{*}{ Calcium } & $<2$ & - & $8(100)$ & - & $0.98(0.11)$ & \multirow{3}{*}{0.983} \\
\hline & $2-3$ & $8(14.8)$ & $40(74.1)$ & $6(11.1)$ & $0.97(0.19)$ & \\
\hline & $\geq 4$ & $4(22.2)$ & $11(61.1)$ & $3(16.7)$ & $0.96(0.23)$ & \\
\hline
\end{tabular}

${ }^{\mathrm{a}}$ Values are expressed as No. (\%).

ber of HD patients. Therefore, in future studies, it is suggested to evaluate nutritional status and gastrointestinal health among patients in different HD centers. With regard to the abounding number of questions in the questionnaires, HD patients were sometimes unable to answer all the questions, and questionnaires were completed by interruptions. It is suggested to perform an interventional study assessing nutritional status by improving HD adequacy.

\subsection{Conclusions}

The present findings indicated that nutritional status in patients undergoing HD had a significant relationship with gastrointestinal health. In addition, since HD adequacy had a significant relationship with gastrointestinal health, use of these findings could facilitate better planning to improve nutritional status, gastrointestinal health, laboratory parameters, and HD adequacy in the management of HD patients, particularly those with mal- 
Table 5. Partial Correlation Coefficients of Laboratory Parameters with Gastrointestinal Health and Nutritional Status Among Hemodialysis (HD) Patients in Semnan, Iran, 2016

\begin{tabular}{|c|c|c|c|c|c|c|c|c|c|}
\hline & & HB & HCT & BUN & $\mathrm{Cr}$ & ALb & ALKP & $\mathrm{Fe}$ & BS \\
\hline \multirow{2}{*}{$\begin{array}{l}\text { Nutritional } \\
\text { status }\end{array}$} & rvalue & 0.102 & 0.145 & -0.072 & 0.079 & -0.130 & 0.419 & -0.003 & -0.073 \\
\hline & Pvalue & 0.379 & 0.208 & 0.535 & 0.495 & 0.259 & $<0.001$ & 0.976 & 0.530 \\
\hline \multirow{2}{*}{$\begin{array}{l}\text { Gastrointestinal } \\
\text { status }\end{array}$} & rvalue & 0.155 & 0.181 & -0.076 & 0.234 & -0.086 & 0.414 & 0.090 & 0.041 \\
\hline & P value & 0.178 & 0.114 & 0.514 & 0.041 & 0.459 & $<0.001$ & 0.437 & 0.727 \\
\hline \multirow{2}{*}{$\begin{array}{l}\text { Dialysis } \\
\text { adequacy }\end{array}$} & rvalue & 0.138 & 0.179 & 0.228 & 0.330 & 0.033 & 0.182 & 0.125 & -0.059 \\
\hline & P value & 0.231 & 0.120 & 0.046 & 0.003 & 0.777 & 0.113 & 0.279 & 0.609 \\
\hline
\end{tabular}

Abbreviations: Alb, albumin; ALKP, alkaline phosphatase; BS, blood sugar; BUN, blood urea nitrogen; $\mathrm{Cr}$, creatinine; HB, hemoglobin; HCT, hematocrit; Fe, ferritin.

nutrition.

\section{Acknowledgments}

We would like to thank the Deputy of Research and Technology of Semnan University of Medical Sciences for the financial and moral support. In addition, we would like to thank the clinical research development unit of Kowsar educational, research, and therapeutic center, Semnan University of Medical Sciences for providing access to the facilities.

\section{Footnotes}

Authors' Contribution: Zaynab Hydarinia-Naieni: study conception and data collection; Monir Nobahar: study conception, data collection/analysis, drafting of the manuscript, critical revision for important intellectual content, and supervision; Raheb Ghorbani: study conception and data analysis.

Funding/Support: The research proposal was approved by the research and ethics committee of Semnan University of Medical Sciences.

\section{Conflicts of Interest: None.}

\section{References}

1. Coresh J, Selvin E, Stevens LA, Manzi J, Kusek JW, Eggers P, et al. Prevalence of chronic kidney disease in the United States. JAMA. 2007;298(17):2038-47. doi: 10.1001/jama.298.17.2038. [PubMed: 17986697].

2. Li Y, Dong J, Zuo L. Is subjective global assessment a good index of nutrition in peritoneal dialysis patients with gastrointestinal symptoms?. Perit Dial Int. 2009;29 Suppl 2:S78-82. [PubMed: 19270237].

3. Salamon K, Woods J, Paul E, Huggins C. Peritoneal dialysis patients have higher prevalence of gastrointestinal symptoms than hemodialysis patients.J Ren Nutr. 2013;23(2):114-8. doi:10.1053/j.jrn.2012.02.007. [PubMed: 22633989].
4. Van Vlem B, Schoonjans R, Vanholder R, De Vos M, Vandamme $\mathrm{W}$, Van Laecke $\mathrm{S}$, et al. Delayed gastric emptying in dyspeptic chronic hemodialysis patients. Am J Kidney Dis. 2000;36(5):962-8. doi: 10.1053/ajkd.2000.19094. [PubMed: 11054352]

5. Strid H, Simren M, Johansson AC, Svedlund J, Samuelsson O, Bjornsson ES. The prevalence of gastrointestinal symptoms in patients with chronic renal failure is increased and associated with impaired psychological general well-being. Nephrol Dial Transplant. 2002;17(8):1434-9. [PubMed: 12147791].

6. Dong R, Guo ZY, Ding JR, Zhou YY, Wu H. Gastrointestinal symptoms: a comparison between patients undergoing peritoneal dialysis and hemodialysis. World J Gastroenterol. 2014;20(32):11370-5. doi 10.3748/wjg.v20.i32.11370. [PubMed: 25170224].

7. Bossola M, Luciani G, Rosa F, Tazza L. Appetite and gastrointestinal symptoms in chronic hemodialysis patients. $J$ Ren Nutr 2011;21(6):448-54. doi:10.1053/j.jrn.2010.09.003. [PubMed: 21239186].

8. Ruperto M, Sanchez-Muniz FJ, Barril G. A clinical approach to the nutritional care process in protein-energy wasting hemodialysis patients. Nutr Hosp. 2014;29(4):735-50. doi: 10.3305/nh.2014.29.4.7222. [PubMed: 24679014]

9. Ikizler TA. Optimal nutrition in hemodialysis patients. Adv Chronic Kidney Dis. 2013;20(2):181-9. doi: 10.1053/j.ackd.2012.12.002. [PubMed: 23439378]

10. Ekramzadeh M, Mazloom Z, Jafari P, Ayatollahi M, Sagheb MM. Major barriers responsible for malnutrition in hemodialysis patients: challenges to optimal nutrition. Nephrourol Mon. 2014;6(6):e23158. doi: 10.5812/numonthly.23158. [PubMed: 25738117].

11. Koefoed M, Kromann CB, Hvidtfeldt D, Juliussen SR, Andersen JR, Marckmann P. Historical Study (1986-2014): Improvements in Nutritional Status of Dialysis Patients. J Ren Nutr. 2016;26(5):320-4. doi: 10.1053/j.jrn.2016.04.005. [PubMed: 27266624].

12. Espahbodi F, Khoddad T, Esmaeili L. Evaluation of malnutrition and its association with biochemical parameters in patients with end stage renal disease undergoing hemodialysis using subjective global assessment. Nephrourol Mon. 2014;6(3):e16385. doi: 10.5812/numonthly.16385. [PubMed: 25032136].

13. Sohrabi Z, Eftekhari MH, Eskandari MH, Rezaeianzadeh A, Sagheb MM Malnutrition-inflammation score and quality of life in hemodialysis patients: is there any correlation?. Nephrourol Mon. 2015;7(3):e27445. doi: 10.5812/numonthly.7(3)2015.27445. [PubMed: 26034747].

14. Herselman M, Moosa MR, Kotze T], Kritzinger M, Wuister S, Mostert D. Protein-energy malnutrition as a risk factor for increased morbidity in long-term hemodialysis patients. J Ren Nutr. 2000;10(1):7-15. doi: 10.1053/JREN01000007. [PubMed: 10671628].

15. Toledo FR, Antunes AA, Vannini FC, Silveira LV, Martin LC, Barretti $\mathrm{P}$, et al. Validity of malnutrition scores for predicting mortality in chronic hemodialysis patients. Int Urol Nephrol. 2013;45(6):1747-52. doi: 10.1007/s11255-013-0482-3. [PubMed: 23793618]. 
16. Panichi V, Cupisti A, Rosati A, Di Giorgio A, Scatena A, Menconi O, et al. Geriatric nutritional risk index is a strong predictor of mortality in hemodialysis patients: data from the Riscavid cohort. $J$ Nephrol. 2014;27(2):193-201. doi:10.1007/s40620-013-0033-0. [PubMed: 24430765].

17. Kalantar-Zadeh K, Tortorici AR, Chen JL, Kamgar M, Lau WL, Moradi H, et al. Dietary restrictions in dialysis patients: is there anything left to eat?. Semin Dial. 2015;28(2):159-68. doi: 10.1111/sdi.12348. [PubMed: 25649719].

18. Todd A, Carroll R, Gallagher M, Meade A. Nutritional status of haemodialysis patients: comparison of Australian cohorts of Aboriginal and European descent. Nephrology (Carlton). 2013;18(12):790-7. doi: 10.1111/nep.12165. [PubMed: 24118237].

19. Nakazato Y, Kurane R, Hirose S, Watanabe A, Shimoyama H. Variability of laboratory parameters is associated with frailty markers and predicts non-cardiac mortality in hemodialysis patients. Clin Exp Nephrol 2015;19(6):1165-78. doi: 10.1007/s10157-015-1108-0. [PubMed: 25788369]

20. Desai AA, Nissenson A, Chertow GM, Farid M, Singh I, Van Oijen MG, et al. The relationship between laboratory-based outcome measures and mortality in end-stage renal disease: a systematic review. Hemodial Int. 2009;13(3):347-59. doi: 10.1111/j.1542-4758.2009.00377.x. [PubMed: 19583604].

21. Rezaiee O, Shahgholian N, Shahidi S. Assessment of hemodialysis adequacy and its relationship with individual and personal factors. Iran J Nurs Midwifery Res. 2016;21(6):577-82. doi: 10.4103/1735-9066.197673. [PubMed: 28194196].

22. Perl J, Dember LM, Bargman JM, Browne T, Charytan DM, Flythe JE, et al. The Use of a Multidimensional Measure of Dialysis Adequacy-Moving beyond Small Solute Kinetics. Clin J Am Soc Nephrol 2017;12(5):839-47. doi: 10.2215/CJN.08460816. [PubMed: 28314806].

23. Kulich KR, Madisch A, Pacini F, Pique JM, Regula J, Van Rensburg CJ, et al. Reliability and validity of the Gastrointestinal Symptom Rating Scale (GSRS) and Quality of Life in Reflux and Dyspepsia (QOLRAD) questionnaire in dyspepsia: a six-country study. Health Qual Life Outcomes. 2008;6:12. doi: 10.1186/1477-7525-6-12. [PubMed: 18237386].

24. Vafaarani Z, Khosravi S, Hekmatpou D, Rafiei F. Effect of Zataria multiflora (Shirazi thyme) on gastrointestinal symptoms in intensive care units nurses. Complement Med J faculty Nurs Midwifery. 2015;5(1):105464.

25. Barzegar H, Moosazadeh M, Jafari H, Esmaeili R. Evaluation of dial- ysis adequacy in hemodialysis patients: A systematic review. Urol J. 2016;13(4):2744-9. [PubMed: 27576879].

26. Hemodialysis Adequacy Work G. Clinical practice guidelines for hemodialysis adequacy, update 2006. Am J Kidney Dis. 2006;48 Suppl 1:S2-90. doi: 10.1053/j.ajkd.2006.03.051. [PubMed: 16813990].

27. Daniels G, Robinson JR, Walker C, Pennings JS, Anderson ST. Gastrointestinal Symptoms among African Americans Undergoing Hemodialysis. Nephrol Nurs J. 2015;42(6):539-48. [PubMed: 26875229] quiz 549.

28. Thomas R, Panackal C, John M, Joshi H, Mathai S, Kattickaran J, et al. Gastrointestinal complications in patients with chronic kidney disease-a 5-year retrospective study from a tertiary referral center. Ren Fail. 2013;35(1):49-55. doi: 10.3109/0886022X.2012.731998. [PubMed: 23078600].

29. Tomizawa M, Shinozaki F, Hasegawa R, Shirai Y, Motoyoshi Y, Sugiyama T, et al. Patient characteristics with high or low blood urea nitrogen in upper gastrointestinal bleeding. World J Gastroenterol. 2015;21(24):7500-5. doi: 10.3748/wjg.v21.i24.7500. [PubMed: 26139996].

30. Wang Y, Xie G, Huang Y, Zhang H, Yang B, Mao Z. Calcium acetate or calcium carbonate for hyperphosphatemia of hemodialysis patients: a meta-analysis. PLoS One. 2015;10(3):e0121376. doi:10.1371/journal.pone.0121376. [PubMed: 25799184].

31. Alyousif Z, Ford AL, Dahl WJ. Calcium Supplementation Does Not Contribute to Constipation in Healthy Women. Can J Diet Pract Res. 2016;77(2):103-5. doi: 10.3148/cjdpr-2015-043. [PubMed: 26771423].

32. Azar AT, Wahba K, Mohamed AS, Massoud WA. Association between dialysis dose improvement and nutritional status among hemodialysis patients. Am J Nephrol. 2007;27(2):113-9. doi: 10.1159/000099836. [PubMed: 17308372].

33. Koor BE, Nakhaie MR, Babaie S. Nutritional assessment and its correlation with anthropometric measurements in hemodialysis patients. Saudi J Kidney Dis Transpl. 2015;26(4):697-701. doi: 10.4103/13192442.160146. [PubMed: 26178540].

34. Chen J, Peng H, Yuan Z, Zhang K, Xiao L, Huang J, et al. Combination with anthropometric measurements and MQSGA to assess nutritional status in Chinese hemodialysis population. Int J Med Sci. 2013;10(8):974-80. doi: 10.7150/ijms.5811. [PubMed: 23801883].

35. Chumlea WC, Dwyer J, Bergen C, Burkart J, Paranandi L, Frydrych A, et al. Nutritional status assessed from anthropometric measures in the HEMO study. J Ren Nutr. 2003;13(1):31-8. [PubMed: 12563621]. 